
\title{
28 Research Suare \\ Thirteen Years Trend in the Magnitude of Urolithiasis and Cholelithiasis in Ethiopia: Evidence from Hospital-Based Retrospective Study
}

Tilahun Alelign ( $\sim$ tilalewa@gmail.com )

Addis Ababa University College of Natural Sciences https://orcid.org/0000-0001-8384-2593

Asfaw Debella

Ethiopian Public Health Institute

Tesfaye Sisay Tessema

Addis Ababa University

Beyene Petros

Addis Ababa University

Research article

Keywords: Cholelithiasis; Ethiopia; Prevalence; Magnitude; Urolithiasis; Trends

Posted Date: August 6th, 2019

DOI: https://doi.org/10.21203/rs.2.12452/v1

License: (c) (i) This work is licensed under a Creative Commons Attribution 4.0 International License.

Read Full License 


\section{Abstract}

Background Recent studies have reported an increasing prevalence of stone diseases (urolithiasis and cholelithiasis) worldwide. However, studies that evaluate the occurrence of stone diseases in Ethiopia are scarce. The objective of this study was to determine trends in the incidence of stone diseases, and the associated comorbidities in Ethiopia during the last 13 years. Methods Thirteen years retrospective data were collected from medical records (Log Books and Electronic Databases) at St. Paulos Tertiary Referral Hospital, September $2005 / 2006$ to $2017 / 2018$. A total of 32,370 surgically treated patients were included in the study. Open surgical treatments related to stone diseases were identified via a thorough review of patient medical records. Data were analyzed using Graph Pad Prism 6 Software. P value $<0.05$ was considered statistically significant. Results Stone diseases were found in 4044 (12.5\%) patients. Of which, the prevalence of urolithiasis was $2.3 \%$, whereas gallstones were $10.2 \%$. In the last 13 years, the trend in stone prevalence has increased by $10.8 \%$ from year $2005 / 6(6.4 \%)$ to $2017 / 18(17.2 \%)$. The prevalence of stone diseases was found to be higher in females $(72.7 \%)$ than in males $(27.3 \%)$. In the case of gallstones, the ratio of females to males was 11.2:1, whereas urinary stones occurred equally in both sexes. The mean age at which the stones occurred was 42 years, and most cases (51.5\%) were prevalent between 30 and 49 years of age. The majority of gallstone patients (65.2\%) were asymptomatic, and most urolithiatic cases $(46.5 \%)$ were located in the kidneys. Comorbidities associated with urolithiasis were the reduction in urinary output, and benign prostatic hyperplasia, whereas hernia and diabetes mellitus were associated with gallstones $(P<0.05)$. Conclusion The prevalence of urolithiasis and gallstones has been increasing over the past 13 years in patients reporting to a referral hospital from different parts of Ethiopia. These findings will raise the awareness of attending physicians and policy makers for prompt treatment interventions and to institute possible prevention measures to minimize stone recurrences. Moreover, research on alternative traditional medicinal treatment must be conducted since there are wide claims in Ethiopian folk medicine about curing stone diseases.

\section{Background}

Urolithiasis and cholelithiasis are public health problems, the prevalence of which has been increasing worldwide [1-3]. Urolithiasis refers to the formation of stone(s) in the urinary tracts [4]. This includes nephrolithiasis (renal calculi, or kidney stones), ureterolithiasis (ureter calculi), and cystolithiasis (bladder calculi) [5-6]. Urolithiasis is mostly lodged in the kidney(s) [7], and is the third common disease of the urinary tract [8]. Nephrolithiasis is a systemic disorder and has been associated with chronic kidney disease (CKD)-end-stage renal failure [9-11], cardiovascular diseases [12], diabetes mellitus, hypertension and obesity [2,13-14]. Even mild CKD is associated with significant adverse cardiovascular events [15]. Clinical manifestations of nephrolithiasis include renal colic, blockage of urine flow, kidney swelling, bloody urine and secondary bacterial infection [16]. This imposes a significant impact on quality of life and the nation's economy [17].

The cause for kidney stones is multi-factorial including epidemiological, biochemical, and genetic factors [18-20]. The pathogenesis of kidney stone formation is a complex biochemical process and remains 
incompletely understood [21]. A kidney stone is formed as the result of an imbalance between promoters and inhibitors in the urine, kidneys [22]. The types of kidney stones are calcium stones, struvite or magnesium ammonium phosphate stones, uric acid stones or urate, cystine or ammonium acid citrate stones and drug-induced stones [23]. Calcium stones comprise about $80 \%$ of the urinary tract stones [24]. After the first episode of a stone, the 10-year recurrence rate is more than $50 \%$ [25-26].

Globally, the prevalence of kidney stones is between $2 \%$ and $20 \%$ [27-28] including infants [29]. It affects approximately 1 in 11 people in the United States [30]. This prevalence may be influenced by variations in sex, age, race, and changes in dietary practices and global warming [4]. Sun exposure enhances vitamin D production which leads to an increase in 25-hydroxy vitamin D [31]. The classic effect of vitamin D is to facilitate the intestinal absorption of calcium by mediating active calcium transport across the intestinal mucosa [32].

In Germany, there has been an increase in the prevalence of urolithiasis within the last 22 years[3]. It was reported that most kidney stones are frequently formed in men than in women between 20 and 49 years old [17]. In addition, Ahuja et al. (33) reported higher stone occurrences in men than in women between the ages of 30 and 39 . In contrast, the majority of kidney stones have been reported to occur in females than males of the age group 20 to 40 [34].

Gallstone disease is a widespread disorder all over the world [35]. Cholesterol-supersaturated bile is the first requirement for gallstone formation, and Gallbladder stores bile secreted from the liver and passes it in response to a fat-rich diet. When the bile contains a high level of cholesterol, it becomes hardened or crystalline to form cholelithiasis or gallstones (Chung-Jyi et al., 2004). The most predominant type of gallstone is cholesterol stone which constitutes more than $80 \%$ of gallstones in the Western world (Acalovschi, 2001). The rare types of gallstones are pigment stones (composed of bile pigments) and the mixed stones (bile salts)(Channa et al., 2007b). In general, cholelithiasis is a leading cause of emergency hospital admission among gastrointestinal problems (Portincasa et al., 2006). Cholecystectomy is one of the most common elective abdominal operations in Europe and the United States. Most gallstones never generate symptoms, but they can cause biliary pain and biliary complications such as acute cholecystitis, jaundice, ascending cholangits, and acute pancreatitis. Such complications of gallstones contribute substantially to health care costs [35].

Beside a genetic predisposition the likelihood of gallstone formation is influenced by some known risk factors. The main risk factors for gallstone formation includes obesity, estrogen treatment and pregnancy $[35,13,36]$ metabolic syndrome [13, 37], Diabetes mellitus [38], being female gender and increasing age $[35,39]$. Moreover, lifestyle modifications such as dietary habits, and lack of physical exercise are also associated with gallstones [40-41]. The risk of developing renal stone is higher among patients with gallstones than without it. Also, the prevalence of gallstones was significantly higher among patients with chronic kidney disease[42]. However, whether renal stones and gallstones share a pathophysiological mechanism remains unclear [39]. 
Globally, the national prevalence of gallstones vary, and over $10 \%$ of people have gallstones in Western countries [43]. There has been an increase in the Hospital admission rates for cholelithiasis in males $(30 \%)$ and in females (64\%) [44], and substantially increased the economic burden on nations' health care systems [45-46]. Gallstones can be asymptomatic or accompanied by various clinical symptoms such as biliary colic, cholecystitis, obstructive jaundice and pancreatitis [47].

The recurrent stone disease causes not only pain and distress in patients, but it also imposes a significant economic burden due to loss of working days and associated health care costs. Currently, less invasive surgical therapies such as extracorporeal shockwave lithotripsy (ESWL), percutaneous nephrolithotomy (PCNL), or ureteroscopy (URS) have revolutionized acute and complex stone management. However, these often result in incomplete stone clearance [49]. Although the analysis of stone chemical composition may influence the choice of intervention [49], open surgery is still the mainstay of treatment [50]. In Ethiopia, reports on the prevalence of urolithiasis and gallstones are scarce. Therefore, the present study intends to determine the prevalence of urolithiasis and gallstone diseases among patients that attended St. Paulos Referral Hospital during the past 13 years (2005/6 to 2017/18).

\section{Materials And Methods}

\section{Study Design and Study population}

Thirteen years retrospective data were extracted from medical records (Log Books and Electronic Databases) between September 2005/2006 and September 2017/2018 from St. Paulos Hospital Millennium Medical College (SPHMC), Addis Ababa, Ethiopia. Electronic medical records were accessed only for 2 years (from 2016/17 to 2017/18 years).

The study population was patients who had been admitted to the St. Paulos Referral Hospital during the study period. Among all patients who underwent open surgery, those identified as stone cases based on a thorough review of patient's clinical records were enrolled in the study. Each clinical history included the age, sex, stone type, stone anatomical locations, co-morbidities, symptomatic or asymptomatic (for gallstones), and stone recurrences. Exclusion criteria were patient records which were incompletely filled and did not appear readable.

\section{Data Analysis}

Data were collected from clinical records by transferring them into Microsoft Excel sheets and analyzed using Graph Pad Prism Version 6 software. The association of stone disease with comorbidities was evaluated using the Chi-square test. P-value $<0.05$ was considered statistically significant.

\section{Results}




\section{The Magnitude of Urolithiasis and Cholelithiasis}

The study population were aged between 3 and 84 years old and the mean age was 42 years. The majority of patients were in the age interval of 30-39 years. In this age group, the highest overall stone incidence was $29.3 \%$ among females. Among males, the highest incidence of overall stone disease was $22.2 \%$ among the age group of 40-49. In general, most stone cases were found between 30 and 49 years of age (Figure 1)..

\section{Trends in Urolithiasis and Cholelithiasis}

Among 32,370 surgically treated patients (open stone removal), 4044 (12.5\%) were found to be stone disease patients. Among these, $2.3 \%$ of patients had renal stone disease and $10.2 \%$ patients had gallstones. Out of 4044 stone cases, urinary calculi were in 757 (18.7\%), whereas gallstones were in 3287 (81.3\%). In the past 13 years, there was a growing trend in stone diseases which has increased by $10.8 \%$ from $2005 / 6(6.4 \%)$ to $2017 / 18(17.2 \%)$. Similarly, the prevalence of urinary stones has increased from $2012 / 13$ to $2017 / 18$ years. On the other hand, cholelithiasis was highest during $2014 / 15$, but lowest during 2008/9 and 2009/10 years (Figure 2). Trends of stone diseases in relation to gender are also presented in Figure 3.

\section{Stone Diseases in Relation to Gender and Age}

In terms of gender, the stone disease was $27.3 \%$, prevalent among males, and $72.7 \%$ prevalent among females. In general, the incidence of stone disease was significantly higher in females than males (female/male ratio: 2.7 to 1) (Figure 4).. Gallstones were more prevalent among females than males (female/male ratio: 11.2 to 1$)(P<0.05)$, but urinary stone occurrence was almost equivalent among both sexes (female/male ratio: 1.1 to 1 (Figure 5)..

As age increased, urolithiasis raised in men and declined in women (Figure 6).. In contrast, the incidence of gallstones reduced as the age increased in females and an increase in males (Figure 7)..

\section{Anatomical Locations of Urolithiasis and Cholelithiasis}

About $46.5 \%$ of urolithiasis were located in the upper urinary tract (the kidneys)(Table 1).. Cholelithiasis was dominate type of gallstone $(96.7 \%)$ located in the gallbladder. The majority of patients with gallstones $(65.2 \%)$ were clinically asymptomatic when they were first diagnosed (Figure 8).. 


\section{The Major Comorbidities Associated with Stone Diseases}

About 103 cases of 757 urolithiasis patients and 65 cases of 3287 gallstone patients were associated with comorbidities or disorders. The major associated comorbidities with gallstones were an umbilical hernia, Diabetes mellitus (DM), hydrops (over-distended gallbladder filled with mucoid), and empyema (acute cholecystitis). Similarly, the common co-morbidities of urolithiasis were a decrease in urinary output (UOP), benign prostatic hyperplasia (BPH), and hydronephrosis (the swelling of kidneys due to an accumulation of urine) (Table 2)..

\section{Discussion}

Urolithiasis is a public health problem which is formed due to an imbalance between promoters and inhibitors in the kidneys. In Ethiopia, reports on the prevalence of urolithiasis and gallstones are scarce. In the current study, the trends in both stone types (kidney stone and gall stones) have been increased across the years. Trends in gallstones have been increased, although it falls during 2016/17 year due to the reduced number of women who visited the hospital to undergo surgery. The incidence of kidney stones has been consistently increasing across the years. This might be due to changes in living style such as diet and daily activities of women and men. There was suggested that the prevalence of stone disease may be associated with increasing consumption of animal proteins and salts, and a decrease in calcium-rich products, genetic basis, and climate warming as reviewed by Alelign and Petros [20].

Globally, the prevalence of urolithiasis varies, ranging from $2 \%$ to $20 \%$ [27-28], whereas gallstones vary between $0.1 \%$ and $61.5 \%$ [51]. In the United States, a National Health Survey report for kidney stone prevalence was 5.2\% (from 1988 to 1994) [2], and in Germany, it was 4.7\% [3]. It is possible that the low urolithiasis figures in our study might be associated with the recent implementations of treatment with extracorporeal shock wave lithotripsy at the St. Paulos Hospital. The variations in stone disease prevalence among the different studies may be linked to differences in the study design, duration of the study, and geographical locations.

In the present study, trends in stone diseases were progressively increased by $10.8 \%$, and urolithiasis has been also linearly increased in the last 5 years (2013/14 to 2018) which was in line with the reports of Raheem et al. [52]. In Japan, the prevalence of renal stones rose from 4 to $5.4 \%$ within 10 years (19751985) [53]. In addition, recurrent urinary tract infections (urease-producing microorganisms) enhance the prevalence of urolithiasis [8,54]. In our study group, most stones were located in the kidneys, which were similar to previous studies [55-56]. Moreover, it should be noted that patients usually visit doctors at the time of acute episodes, and the utilization of more accurate diagnostic tools may overestimate stone prevalence.

In the current study, the prevalence of urolithiasis $(2.3 \%)$ was substantially higher than the prevalence $(0.24 \%)$ reported by Masterson et al.[57], but lower than the prevalence (8.8\%) in the United States [30], 
and in Iran (5.7\%) [58]. In our study, the prevalence of kidney stone in women was equivalent to men. Previous studies described that the female sex hormone (estrogen) inhibits calcium oxalate stone formation [59], whereas testosterone promotes it in male albino Wistar rats [60]. It was also supported by Curhan [61] indicating that males have a three times higher urinary stone incidence compared to females due to the sex hormone. Urolithiasis mainly occurs in the third and fourth decades of life when the level of serum testosterone is also the highest [62]. Similarly, a study also reported that higher androgen level was diagnosed in renal stone patients compared with the healthy controls [63]. However, similar studies indicated that urolithiasis was more frequent among men than women [2,55]. In Iran, it was reported that urinary stones were frequent in males (6.1\%) than females (5.3\%)[58]. Additionally, kidney stones were prevalent among men (6.3\%) than in women (4.1\%)[64]. The reports of Scales et al.[30] also indicated that the prevalence of renal stone was $10.6 \%$ among men, and $7.1 \%$ among women. Lieske et al. [65] reported that the male-to-female ratio was reduced from 3.1 to 1.3 during the last 30 years (1970-2000) in the Rochester population. In other words, renal stones increased by $1.9 \%$ per year in women, but declined by $1.7 \%$ per year in men. Similarly, this was consistent with the study revealing an increased incidence of kidney stone in young women than men [66].

In our study, the $10.2 \%$ gallstone prevalence was higher than reports in Gondar University Hospital (5.2\%) [67], and nearly close to $8.6 \%$ gallstone prevalence in Saudi Arabia [68]. Females were frequently affected by gallstones than men with a ratio of 11.2:1, which was similar to the reports of Gomati et al. [46]. Studies have shown that the prevalence of gallstone disease was two to three times higher among women than men. Although it is common in young women and rare in young men, the difference narrows with increasing age [35]. It is presumed that female sex hormones are more likely to be responsible for gallstone increased risk [59]. Estrogen increases biliary cholesterol secretions (especially during pregnancy) and results in cholesterol supersaturation of bile [35]. Previous reports also suggested that cholesterol saturation increases in the elderly due to reductions in the bile acid synthesis both in men and women [69]. On the other hand, hormone replacement therapy in post- menopausal women and oral contraceptives have also been described to be associated with an increased risk for gallstone disease [35].

The overall stone prevalence predominantly affects both genders from 30 to 49 years, similar to the reports of Hussain [70]. In our study, the mean age at the time of stone treatment was 42 years, which was similar to a study that reported the mean age of 45 years in men and 41 years in women [65]. A related study in Iceland revealed that renal stone prevalence was in the age range of 30 to 79 years [27]. However, there is also another study that showed younger age groups not to be fully free from developing kidney stones [71].

Our finding that Diabetes mellitus was one of the major comorbidities associated with gallstones, which were consistent with the findings of other studies [72-73]. Although diabetes and hypertension have been significantly associated with stone diseases, affecting children as young as 5 years old [74] these were not associated with urolithiasis in the current study. 
This study has the following limitations. The retrospective study design cannot be viewed as fairly representative of the general population since it is based on patients that come to the hospitals seeking treatment, as a result of which it may overestimate the prevalence of stone diseases. On the other hand, some erroneous and incomplete coding of patients' medical information could have limited our effort to capture all hospital's admitted events. Furthermore, since the extracorporeal shock wave lithotripsy treatment performed on outpatients was not included under surgical treatment records, this will also lead to under reporting of stone diseases. Despite these limitations, the strength of the present study was its inclusion of a large number of subjects (patients) who underwent surgical treatment.

\section{Conclusion}

Our findings showed that both gallstones and urinary tract stones are public health problems in Ethiopia. The overall prevalence of stone diseases among Hospital admitted patients in one referral Hospital of Ethiopia was $12.5 \%$, of which, the prevalence of urolithiasis was $2.3 \%$, whereas gallstones represent $10.2 \%$. In the last 13 years, trends in overall stone prevalence were increased by $10.8 \%(6.4 \%$ to $17.2 \%)$. This study provides baseline information for researchers and would guide policy makers to pay attention to the instituting preventative measures to minimize stone diseases in the population.

\section{Declarations}

\section{Ethical Approval}

The research protocol was approved by the College of Natural Sciences Institutional Review Board (CNSIRB) (Approval Minute No. IRB/021/2016), Addis Ababa University. Furthermore, permission was also obtained from the St. Paulos Hospital, Millennium Medical college (SPHMC) Institutional Review Board (Ref. No. PM23/285/2016). To ensure confidentiality, the patient's name was assigned to code identifiers, and data were used only for the intended study.

\section{Availability of data and materials}

Data supporting the findings are presented within the manuscript. The data sets used and/or analyzed during the current study available from the corresponding author on reasonable request.

\section{FundingFunding for this study was not provided.}

\section{Competing Interest}

All authors declare that they have no competing interests. 


\section{Consent for publicationNot applicable.}

\section{Authors' Contributions}

TA: conceived the project idea, gathering and analyzed data, and drafted the manuscript; BP: involved in the evaluation of the study protocol, and manuscript preparations; TS and AD: involved in the manuscript proofreading. All authors approved the final manuscript.

\section{Author details}

1 Department of Microbial, Cellular, and Molecular Biology, College of Natural Sciences, Addis Ababa University, P. O. Box 1176, Addis Ababa, Ethiopia

2 Ethiopian Public Health Institute, Traditional and Modern Medicine Directorate, Ethiopia

3 Institute of Biotechnology, Addis Ababa University, P.O.Box 1176, Addis Ababa, Ethiopia

\section{Acknowledgments}

The authors would like to thank the Staff of Surgery Department, St. Paulos Referral Hospital, giving Space and access to review the required medical records of patients. Especially we acknowledge Mr. Mikias and Mr. Efrem for their unreserved support in providing the required medical records. Moreover, we thank W/o Zinayitu Tafere for her inputs during data collection. We also would like to thank Dr. Guadie Sharew (MD) for his vital comments on the manuscript.

\section{References}

1. Acalovschi M. (2001). Cholesterol gallstones: from epidemiology to prevention. Postgrad Med J. 77:221-229.

2. Stamatelou K. K., Francis M. E., Jones C. A., Nyberg L. M. and Curhan G. C. (2003). Time trends in reported prevalence of kidney stones in the United States: 1976-1994. Kidney Int., 63(5):1817-1823.

3. Hesse A., Brandle E., Wilbert D., Kohrmann K. U. and Alken P. (2003). Study on the prevalence and incidence of urolithiasis in Germany comparing the years 1979 vs 2000. Eur Urol., 44(6):709-713.

4. Romero V., Akpinar H. and Assimos D. G. (2010). Kidney Stones: A global Picture of Prevalence, Incidence, and Associated Risk Factors. Rev Urol., 12(2/3):e86-e96.

5. Havagiray R., Shashi A. C., Jain S. K. and Monika S. (2010). Herbal treatment for urinary stones. IJPSR., 1(2): 1412-1420.

6. Borisov V. V. and Dzeranov N. K. (2011). Urolithiasis: Therapy of patients with kidney and ureter stones. Moscow: Publishing House of the Russian Society of Urologists, p. 88. 
7. Atodariya U., Barad R., Upadhyay S. and Upadhyay U. (2013). Anti-urolithiatic activity of Dolichos biflorus seeds, J Pharm Phytochem., 2(2): 209-213.

8. Noshad H, Ahmadpour F, Soltanpour B. and Ghojazadeh M. (2014). Study of renal stones complications in 200 patients in Tabriz, Iran. J Anal Res Clin Med., 2(4): 187-92.

9. El-Zoghby Z. M., Lieske J. C., Foley R. N., Bergstralh E. J., Li X., Melton 3rd L. J., Krambeck A. E. and Rule A.D. (2012). Urolithiasis and the risk of ESRD. Clin J Am Soc Nephrol., 7(9):1409-15.

10. Mikawlrawng K., Kumar S., and Raunak V. (2014). Current scenario of urolithiasis and the use of medicinal plants as antiurolithiatic agents in Manipur (North East India): A Review: IJHM., 2 (1): 112.

11. Rule A.D., Bergstralh E. J., Melton L. J., Li X., Weaver A. L. and Lieske J. C. (2009). Kidney stones and the risk of chronic kidney disease. Clin J Am Soc Nephrol., 4(4):804-811.

12. Rule A.D., Roger V. L., Melton 3rd L. J., Bergstralh E. J., Li X., Peyser P. A., Krambeck A. E. and Lieske J. C. (2010). Kidney stones associate with increased risk for myocardial infarction. J Am Soc Nephrol., 21(10):1641-4.

13. Taylor E. N., Stampfer M. J. and Curhan G. C. (2005). Obesity, weight gain, and the risk of kidney stones. JAMA., 293(4):455-462.

14. Uyeturk U., Dagıstan E., Aktas G., Ozyalvacli M.E, Tekce H. and Yilmaz B. (2014). Association between urinary stone disease and perirenal tissue thickness. NJ Med Res., 4(3): 193-196.

15. Go A. S., Chertow G. M., Fan D., McCulloch C. E. and Chi-yuan Hsu C.-Y. (2004). Chronic kidney disease and the risks of death, cardiovascular events, and hospitalization. N Engl J Med., 351:12961305.

16. Murugan V. M. and Satishkumar A. S. (2001). Effect of Aerva lanata leaf extract and Vediuppu chunnam on the urinary risk factors of calcium oxalate urolithiasis during experimental hyperoxaluria. Pharmacol Res., 43: 89-93.

17. Baheti D. G. and Kadam S. S. (2013). Antiurolithiatic activity of some traditional medicinal plants against calcium oxalate induced urolithiasis in rats. IJPCBS., 3(4): 1276-1285.

18. Moe O. W. (2006). Kidney stones: Pathophysiology and medical management. Lancet, 367: 333-44.

19. Alaya A., Belgith A., Hammadi S., Nouri A. and Najjar M. F. (2012). Kidney Stones in Children and Teenagers in the Central Coast Region of Tunisia. Iran J Pedia., 22(3): 290-296.

20. Alelign T. and Petros B. (2018). Kidney Stone Disease: An Update on Current Concepts. Advances in Urology. Volume 2018, Article ID 3068365, 12 pages.

21. Agarwal K. and Varma R. (2013). Evaluation of the in-vitro anti-urolithiasis activity of Portulaca oleracea L. Pharmanest. An Int. J. Adv. Pharm. Sci., 4 (6):1284-1293.

22. Finlayson B. (1974). Symposium on renal lithiasis. Renal lithiasis in review. Urol Clin North Am., 1:181-212.

23. Barbasa C., Garciaa A., Saavedraa L. and Muros M. (2002). Urinary analysis of nephrolithiasis markers. J Chromatogr B., 781: 433-455. 
24. Coe F. L., Evan A. and Worcester E. (2005). Kidney stone disease. J Clin Invest., 115(10): 2598- 2608.

25. Trinchieri A., Ostini F., Nespoli R., Rovera F., Montanarl E. and Zanetti G. (1999). A prospective study of recurrence rate and the risk factor for recurrence after a first renal stone. J Urol., 162:27-30.

26. Ljunghall S. and Danielson B. G. (1984). A prospective study of renal stone recurrences. Br J Urol., $56: 122-4$.

27. Indridason O. S., Birgisson S., Edvardsson V. O., Sigvaldason H., Sigfusson N. and Palsson R. (2006). Epidemiology of kidney stones in Iceland: A population-based study. Scand J Urol Nephrol., 40:21520.

28. Buchholz N. P., Abbas F., Afzal M., Khan R., Rizvi I. and Talati J. (2003). The prevalence of silent kidney stones: An ultrasonographic screening study. J Pak Med Assoc., 53: 24-25.

29. Al-Eisa A. A., Al-Hunayyan A. and Gupta R. (2002). Pediatric urolithisis in Kuwait. Int Urol Nephrol. 33(1):3-6.

30. Scales Jr. C. D., Smith A. C., Hanley J. M., and Saigal C. S. (2012). Prevalence of Kidney Stones in the United States. Eur Urol., 62(1): 160-165.

31.Penniston K.L, Jones A. N., Nakada S. Y. and Hansen K. E. (2009). Vitamin D repletion does not alter urinary clacium excretion in healthy postmenopausal women. BJU Int.,, 104:1512-1516.

1. Heaney R..P. (2008). Vitamin D and calcium interactions: functional outcomes. Am J Clin Nutr., 88(suppl):541-4.

2. Ahuja A., Al-Risi A. O. Z. and Ali N. M. (2014). Study on Prevalence and Management of Renal Stones among Omani in Patients at Sohar Hospital. Sch. J. App. Med. Sci., 2(1):22-33.

3. Qadami E., Ampoon, A. and Manansala N. H. (2013). The prevalence and clinical profile of patients diagnosed with renal calculi at the American Mission Hospital in the Kingdom of Bahrain. J Bahrain Med Soc., 24 (2): 62-65.

4. Novacek G. (2006). Gender and Gallstone Disease. Wien Med Wochenschr., 156/19-20: 527-533.

5. Johnston D. E. and Kaplan M. M. (1993). Pathogenesis and treatment of gallstones. N Engl J Med., 328:412-21.

6. Tsai C. J., Leitzmann M. F., Willett W. C. and Giovannucci E. L. (2006). Weight cycling and risk of gallstone disease in men. Arch Intern Med., 166(21):2369-2374.

7. Diehl A. (1991). Epidemiology and natural history of gallstone disease. Gastroenterol Clin North Am., 20: 1-19.

8. Li C. H., Sung F. C., Wang Y.-C., Lin D. and Kao C. H. (2014). Gallstones increase the risk of developing renal stones: A nationwide population-based retrospective cohort study. Q J Med., 107:451-457.

9. Nielsen S. J. and Popkin B. M. (2003). Patterns and trends in food portion sizes, 1977-1998. JAMA., 289(4):450-453.

10. Despres J. P. (2005). Our passive lifestyle, our toxic diet, and the atherogenic/diabetogenic metabolic syndrome: can we afford to be sedentary and unfit? Circulation, 112(4):453-455. 
11. Lai S.-W., Liao K.-F., Lai H.-C., Chou C.-Y., Cheng K. C., and Lai Y.-M. (2009). The Prevalence of Gallbladder Stones is Higher among Patients with Chronic Kidney Disease in Taiwan. Med., 88: 46 51.

12. Juvonen T. (1994). Pathogenesis of gallstones. Scand J Gastroenterol., 29: 577-582.

13. Kang J.-Y., Ellis C., Majeed A., Hoare J., Tinto A., Williamson R. C. N., Tibbs C. J. and Maxwell J. D. (2003). Gallstones - an increasing problem: A study of hospital admissions in England between 1989/1990 and 1999/2000. Aliment Pharmacol Ther., 17: 561-569.

14. Stringer M. D., Fraser S., Gordon K. C., Sharples K. and Windsor J. A. (2013). Gallstones in New Zealand: Composition, risk factors, and ethnic differences. ANZ J Surg., 83:575-80.

15. Gomati A., Elafi S. and Rafe H. (2014). A study on the risk factors for Gallbladder diseases in Elkhoms Teaching Hospital, Libya. IOSR-JDMS., 13(2): 01-04.

16. Portincasa P., Moschetta A. and Palasciano G. (2006). Cholesterol gallstone disease. Lancet, 368:230-9.

17. Mittal A., Tandon S., Singla S. K. and Tandon C. (2015). In vitro inhibition of calcium oxalate crystallization and crystal adherence to renal tubular epithelial cells by Terminalia arjuna. Urolithiasis, 44:117-125.

18. Channa N. A., Ghangro A. B., Soomro A.M. and Noorani L. (2007a). Analysis of kidney stones by FTIR spectroscopy. JLUMHS., 66-73.

19. Hounnasso P. P., Avakoudjo J. D. G., Paré A. K., Brahima K., Ouattara A., Agounkpé M. M., Natchagandé G., Toré S. R., Mustapha A. B. and Vodounou A. (2015). Symptomatic Urinary Lithiasis: Epidemiology and Management at Urology Department of University Hospital of Cotonou. J Urol., 5: 7-12.

20. Shaffer E. A. (2006). Gallstone disease: Epidemiology of gallbladder stone disease. Best Pract Res Clin Gastroenterol., 20:981-96.

21. Raheem O. A., Khandwala Y. S., Sur R. L., Ghani K. R. and Denstedt J. D. (2017). Burden of Urolithiasis: Trends in Prevalence, Treatments, and Costs. Eur Urol., 3:18-26.

22. Yoshida O. and Okada Y. (1990). Epidemiology of urolithiasis in Japan: A chronological and geographical study. Urol Int., 45:104-11.

23. Dursun I., Poyrazoglu H. M., Dusunsel R., Gunduz Z., Gurgoze M. K., Demirci D. and Kucukaydın M. (2008). Pediatric urolithiasis: An 8-year experience of a single center. Int Urol Nephrol., 40:3-9.

24. Alaya A., Nouri A. and Najjar M. F. (2009). Urolithiasis in Tunisian Children: A Study of 100 Cases. Saudi J Kidney Dis Transpl., 20(6):1096-1100.

25. Ahmad F., Nada M.O, Farid A. B., Haleem M. A. and Razack S. M. A. (2015). Epidemiology of Urolithiasis with Emphasis on Ultrasound Detection: A Retrospective Analysis of 5371 Cases in Saudi Arabia. Saudi J Kidney Dis Transpl., 26(2):386-391.

26. Masterson J. H., Phillips C. J., Crum-Cianflone N. F., Krause R. J., Sur R. L. and L'Esperance J. O. (2017). A 10-Year Retrospective Review of Nephrolithiasis in the Navy and Navy Pilots. J Urol., 
02.074.

27. Safarinejad M. R. (2007). Adult urolithiasis in a population-based study in Iran: prevalence, incidence, and associated risk factors. Urol Res., 35:73-82.

28. Iguchi, M., Takamura, C., Umekawa, T., Kurita, T. and Kohri, K. (1999). Inhibitory effects of female sex hormones on urinary stone formation in rats. kidney Int., 56,:479-485.

29. Lee, Y. H., Huang, W. C., Huang, J. K. and Chang, L. S. (1996). Testosterone enhances whereas estrogen inhibits calcium oxalate stone formation in ethylene glycol treated rats. J Urol., 156, 502505.

30. Curhan G. C. (2007). Epidemiology of stone disease. Urol Clin North Am., 34:287-293.

31. Travison T. G., Araujo A. B., Hall S. A. and McKinlay J. B. (2009). Temporal trends in testosterone levels and treatment in older men. Curr Opin Endocrinol Diabetes Obes., 16:211-217.

32. Naghii M. R., Babaei M. and Hedayati M. (2014). Androgens Involvement in the Pathogenesis of Renal Stones Formation. PLoS ONE, 9(4): e93790.

33. Pak C. Y. (1998). Kidney stones. Lancet, 351:1797-1801.

34. Lieske J. C., Peña de la Vega L. S., Slezak J. M., Bergstralh E. J., Leibson C. L., Ho K. L. and Gettman M. T. (2006). Renal stone epidemiology in Rochester, Minnesota: An update. Kidney Int., 69:760- 764.

35. Tasian G. E., Ross M. E., Song L., Sas D. J., Keren R., Denburg M. R., Chu D. I., Copelovitch L., Saigal C. S. and Furth S. L.(2016). Annual Incidence of Nephrolithiasis among Children and Adults in South Carolina from 1997 to 2012. Clin J Am Soc Nephrol., 11: 488-496.

36. Getachew A. (2008). Epidemiology of gallstone disease in Gondar University Hospital as seen in the Department of Radiology. Ethiop J Health Dev., 22(2):206-211.

37. Alishi Y. A., Howaish F. H., Alhamdan F. A., Almalki A. A., Alqahtani S. A., Alharthi S. A., Alanazi A. S. and Alsuroji A. H. S. (2017). Prevalence and Risk Factors for Gallstones among Population in Riyadh City, KSA 2017. EJHM., 69 (5):2384-2388.

38. Einarsson K., Nilsell K., Leijd B., and Angelin B. (1985). Influence of age on the secretion of cholesterol and synthesis of bile acids in the liver. N Engl J Med., 313:277-82.

39. Hussain S. M. (2013). A retrospective study to determine the type and fate of urinary calculi incidence among urinary patients. America J Res Commun., 1(2): 56-65.

40. Alatab S., Pourmand G., Howairis M. F. E. L., Buchholz N., Najafi I., Pourmand M. R., Mashhadi R. and Pourmand N.(2016). National Profiles of Urinary Calculi. A Comparison Between Developing and Developed Worlds. Iran J Kidney Dis.,10 (2): 51-61.

41. Sodhi J. S., Zargar S. A., Khateeb S., Showkat A., Javid G., Laway B. A., Parveen S., Khan B. A., Yattoo G. N., Shah A., Gulzar G. M. and Khan M. A. (2014). Prevalence of gallstone disease in patients with type 2 diabetes and the risk factors in North Indian population: A case-control study. Indian J Gastroenterol., 33: 507-511.

42. Ansari-Moghaddam A., Khorram A., Miri-Bonjar M., Mohammadi M. and Ansari H. (2016): The Prevalence and Risk Factors of Gallstone Among Adults in South-East of Iran: A Population-Based 
Study. J Health Sci , 8: 60-67.

43. Schaeffer A. J., Feng Z., Trock B. J., Mathews R. I., Neu A.M., Gearhart J. P. and Matlaga B. R. (2011). Medical Comorbidities Associated With Pediatric Kidney Stone Disease. Urol., 77 (1): 195-199.

\section{Tables}

Table 1. The frequency of urolithiatic anatomical locations among 757 cases at SPHMC, September 2005 to September 2018.

\begin{tabular}{ll} 
Urolithiatic locations & Number of cases (\%) \\
\hline Urolithiasis (\#757) & \\
\hline Kidneys & $352(46.5)$ \\
\hline Ureter & $314(41.5)$ \\
\hline Bladder & $89(11.7)$ \\
\hline Urethra & $2(0.3)$ \\
\hline Kidney stones(\#757) & \\
\hline Right & $332(43.9)$ \\
\hline Left & $268(35.4)$ \\
\hline Not defined & $157(20.7)$ \\
\hline Ureteric stones (\#314) & \\
\hline Right & $153(48.7)$ \\
\hline Left & $126(40.1)$ \\
\hline Not defined & $35(11.1)$
\end{tabular}

Note: \# - represents a number

Table 2. Commonly encountered co-morbidities with stone diseases at SPHMC, September 2005 to September 2018 ( $n=168$ cases). 


\begin{tabular}{llll} 
NNo. & Co-morbidities & $\begin{array}{l}\text { Urinary stones } \\
(\mathrm{n}=103 \text { cases, 61.3\% })\end{array}$ & $\begin{array}{l}\text { Gallstones } \\
(\mathrm{n}=65 \text { cases, 38.7\%) }\end{array}$ \\
\hline & & No. pts $(\%)$ & No. pts $(\%)$ \\
\hline 1 & BPH & - \\
\hline 2 & Reduced UOP & $58(34.5)$ & - \\
\hline 3 & Hydronephrosis & $6(3.6)$ & - \\
\hline 4 & Kidney failure & $4(2.4)$ & - \\
\hline 5 & Diabetes mellitus (Type 2) & $1(0.5)$ & $12(7.1)$ \\
\hline 6 & Recurrent & $10(6)$ & $1(0.6)$ \\
\hline 7 & Empyema & - & $7(4.2)$ \\
\hline 7 & Jaundice & - & $4(2.4)$ \\
\hline 8 & Umbilical hernia & - & $27(16.1)$ \\
\hline 9 & Hydrops & - & $13(7.7)$ \\
\hline 10 & Kidney stone & - & $1(0.6)$
\end{tabular}

Abbreviations: No. pts - the number of patients; $\mathrm{BPH}$ - benign prostatic hyperplasia; Urine output (UOP); Significant $(P<0.05)$.

\section{Figures}

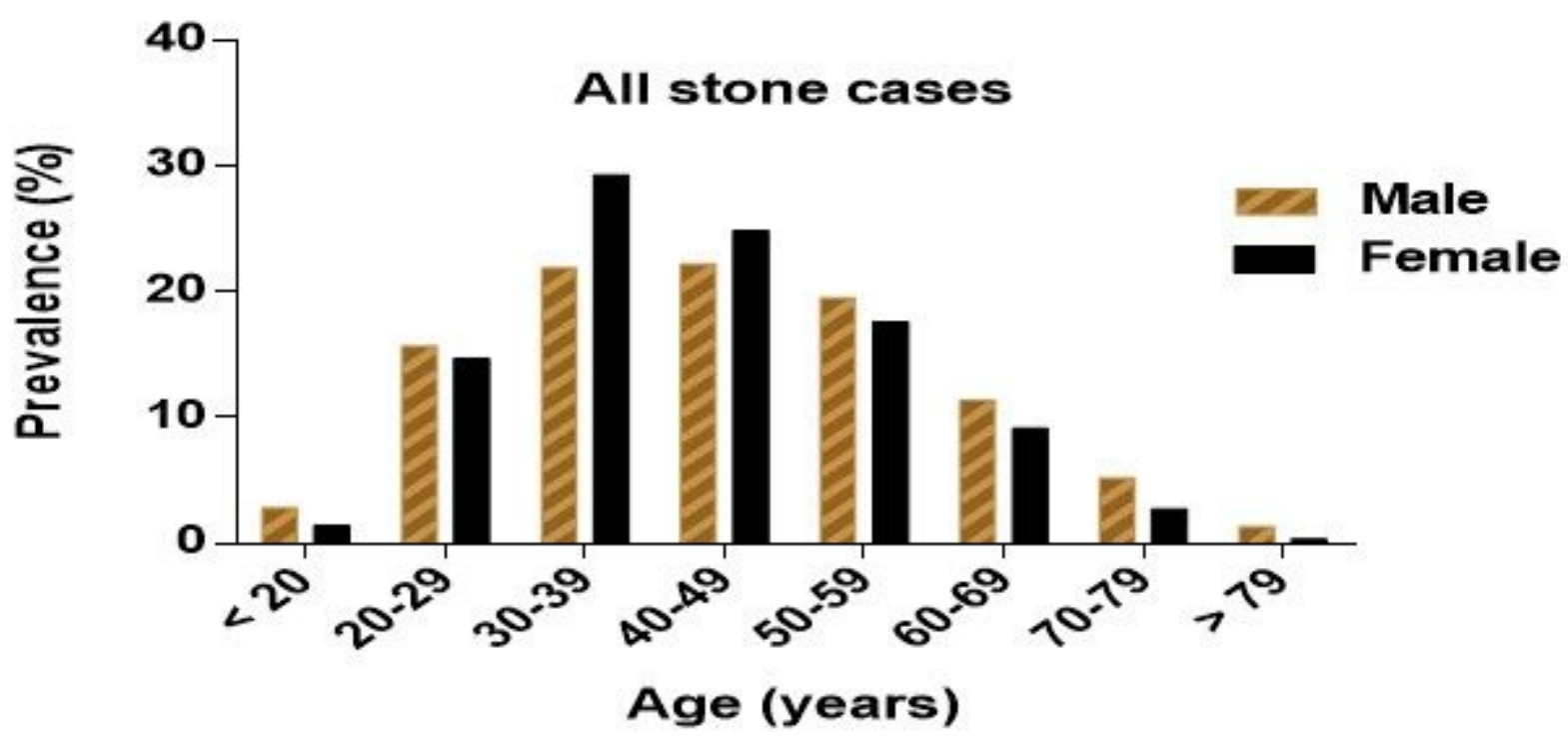

Figure 1 

2018.

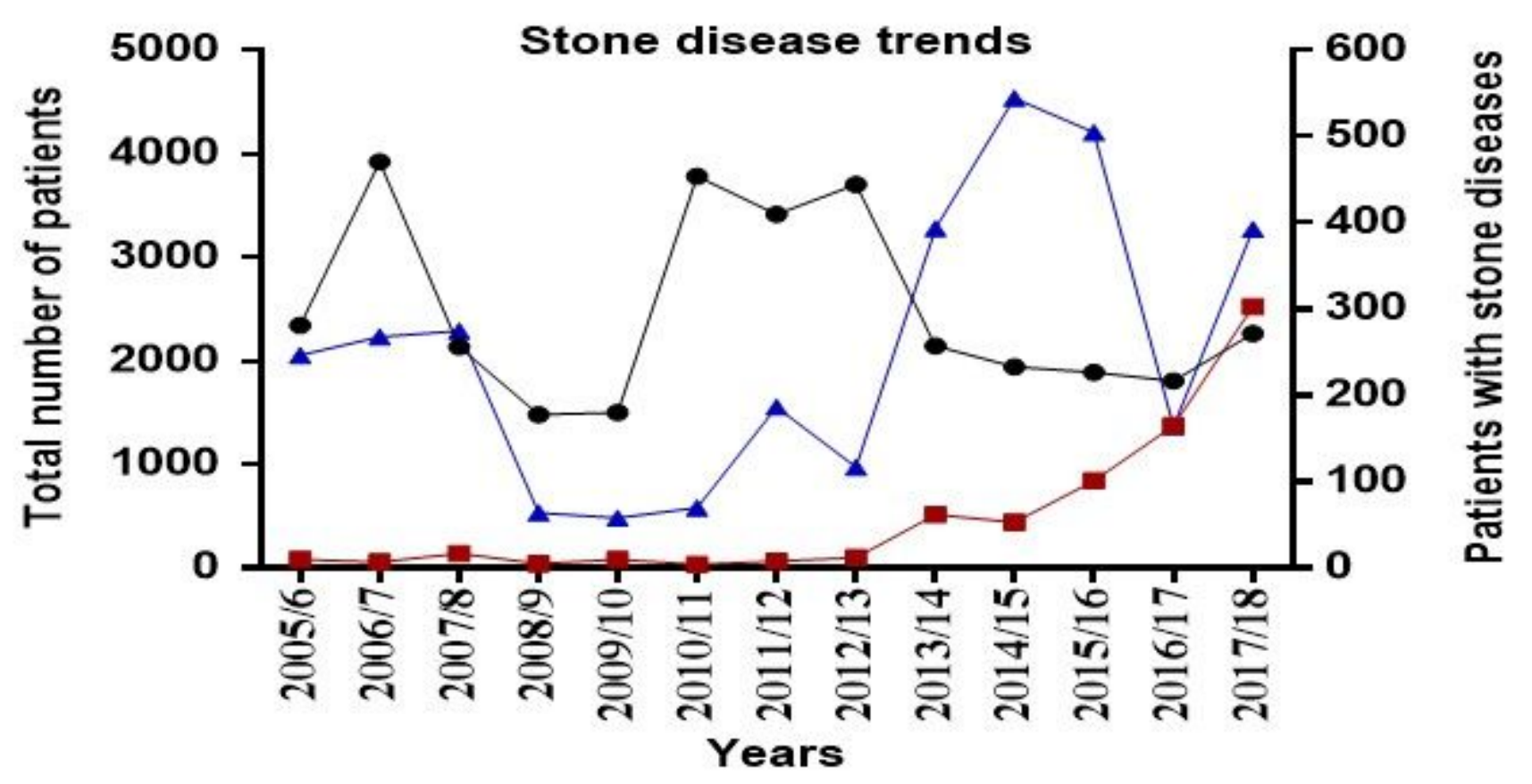

$\bullet$ Total surgery $\rightarrow$ Urolithiasis $\rightarrow$ Cholelithiasis

Figure 2

Trends in stone disease prevalence in the past 13 years (September 2005 to September 2018) at St. Paulos Hospital Millennium Medical College (SPHMC). [Note: The left Y-axis represents the overall surgical cases (including non-stone cases), whereas the right $\mathrm{Y}$-axis represents only stone cases (urolithiasis and cholelithiasis)].

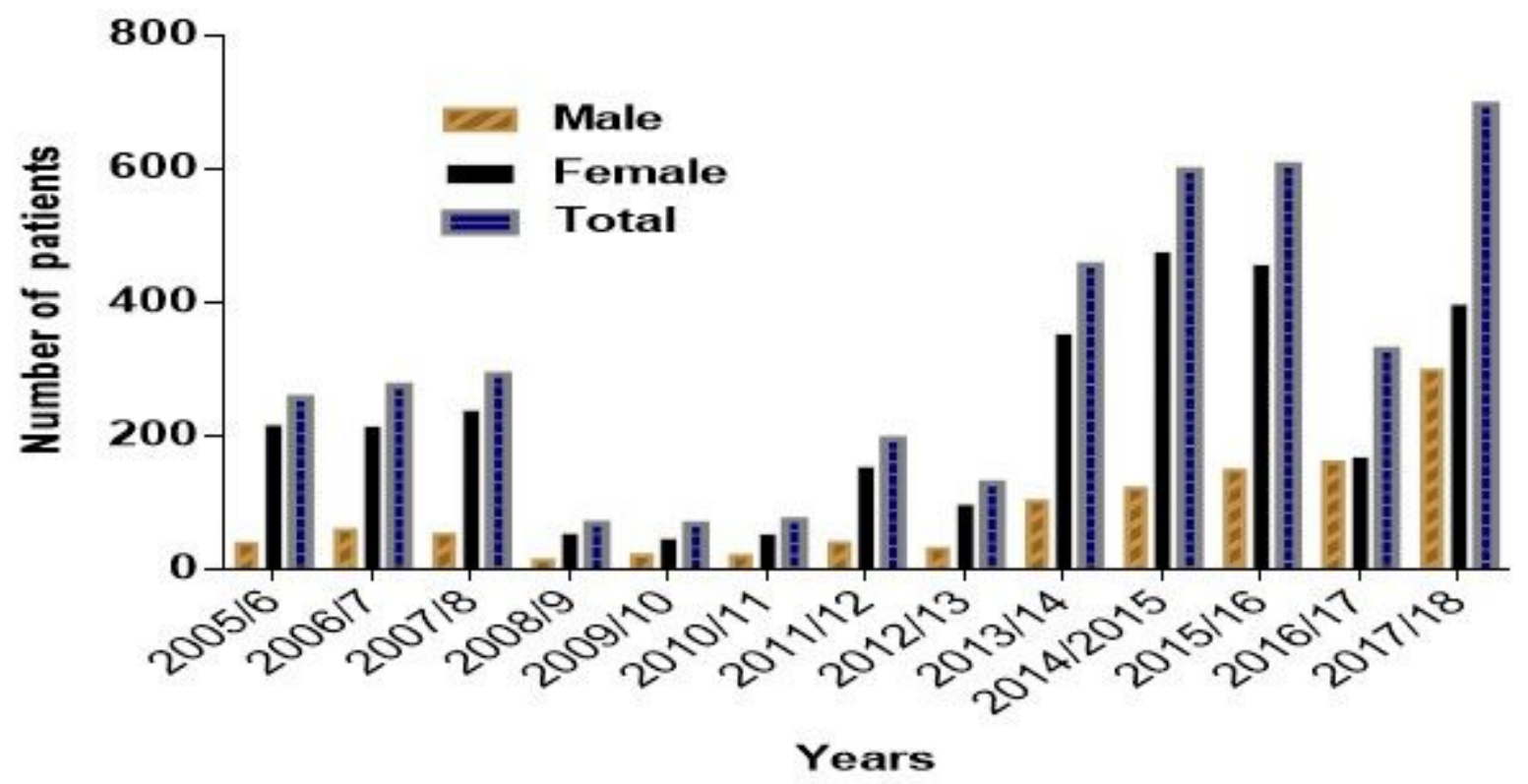

Figure 3 
Trends in stone disease prevalence as it relates to gender in the past 13 years (September 2005 to September 2018) at St. Paulos Hospital Millennium Medical College (SPHMC).

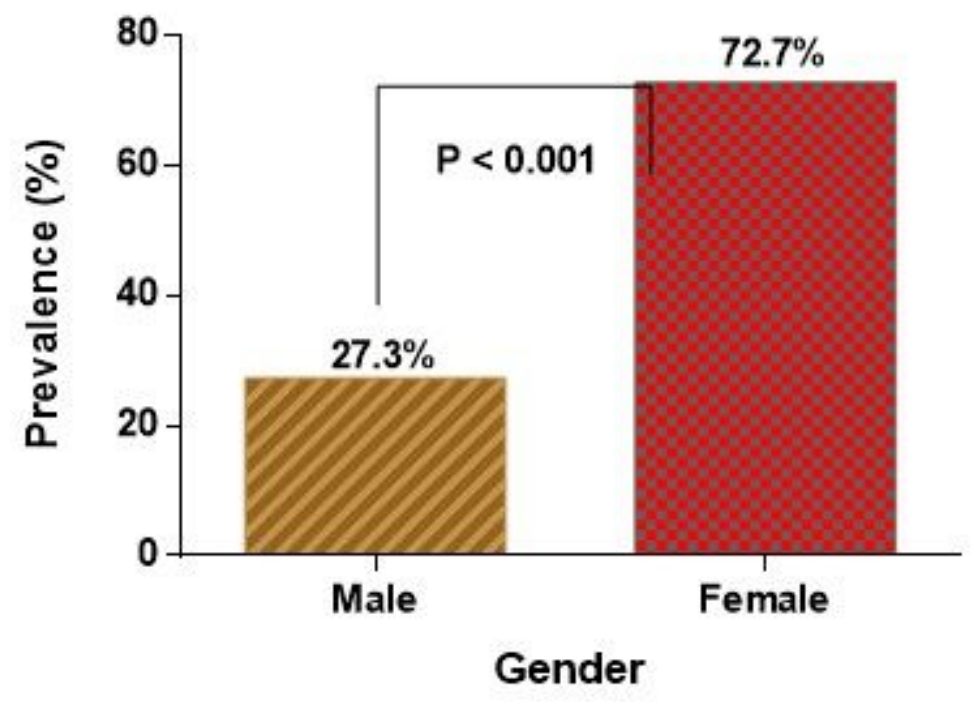

Figure 4

The overall stone disease prevalence as a function of gender among 4044 patients at SPHMC, September 2005 to September 2018.

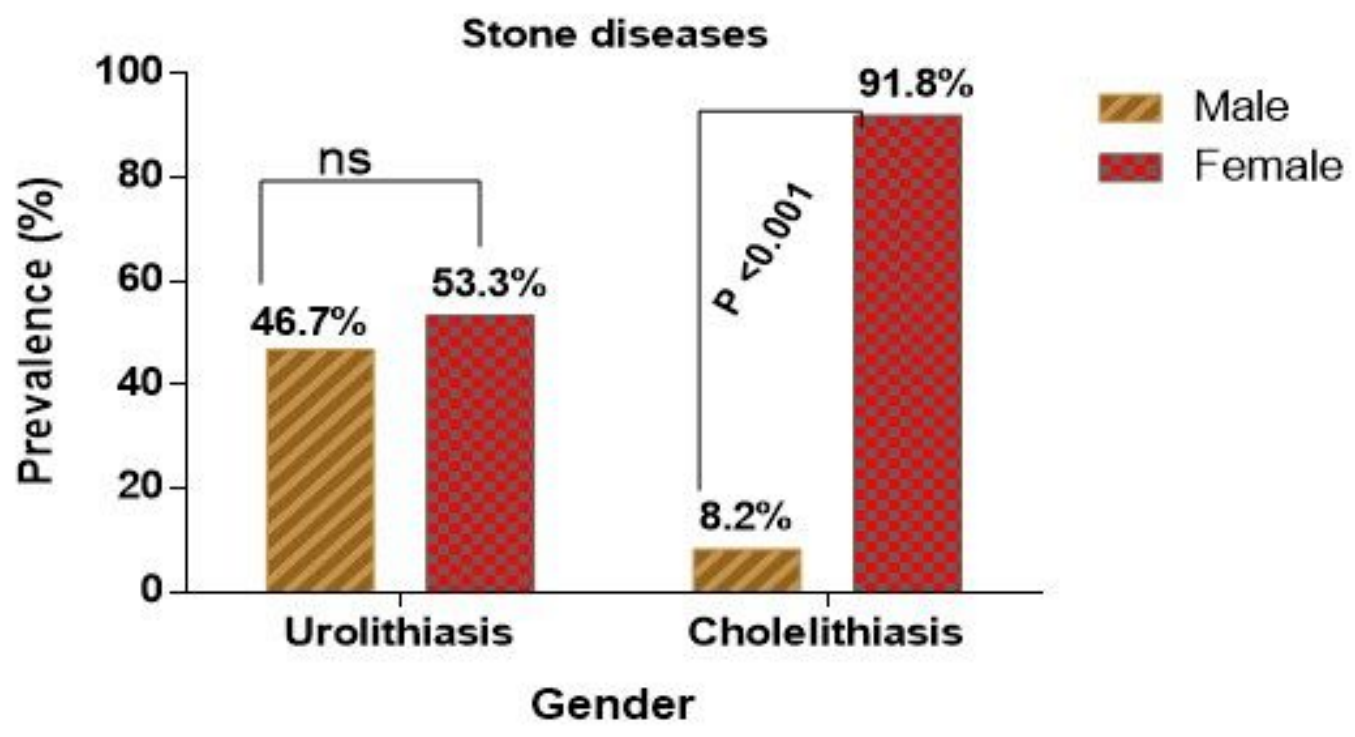

Figure 5

The frequency of urolithiasis and cholelithiasis as a function of gender among 4044 cases at SPHMC, September 2005 to September 2018. [ns - not statistically significant]. 


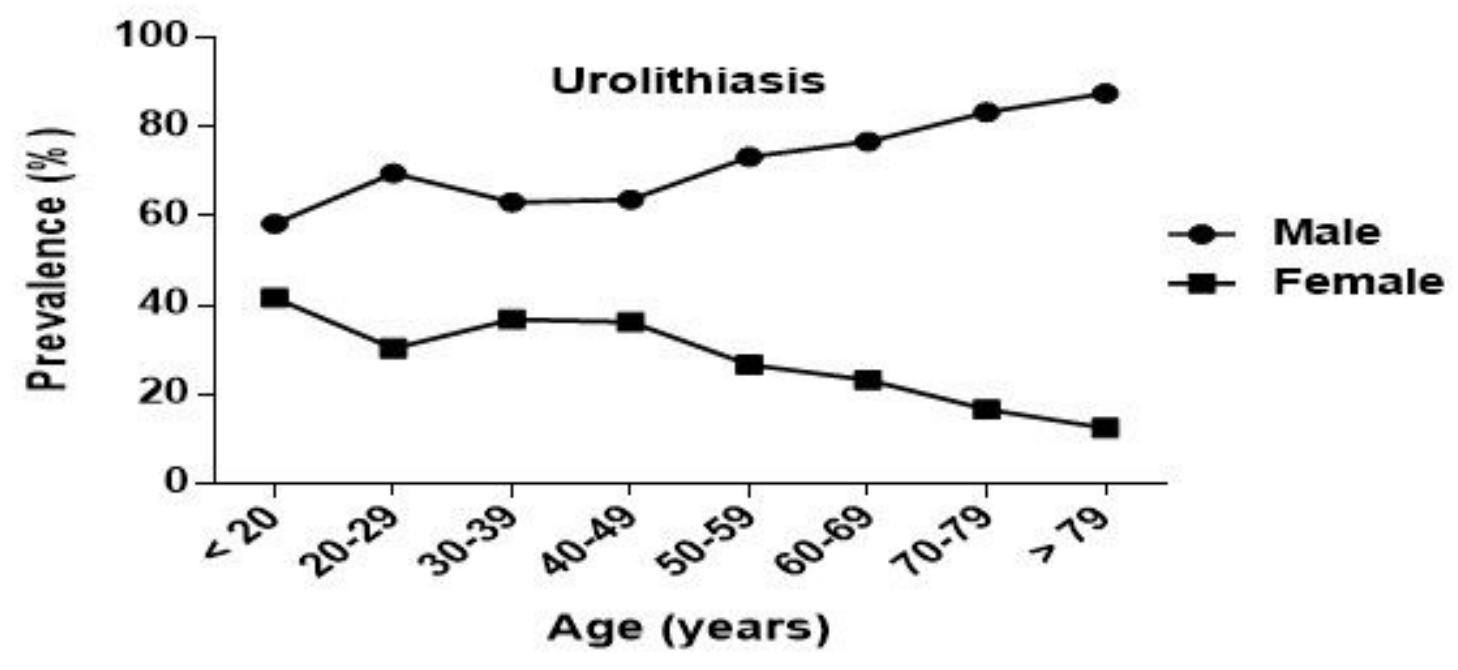

Figure 6

Percentage of patients with urolithiasis as a function of gender and age among 4044 cases at SPHMC, September 2005 to September 2018.

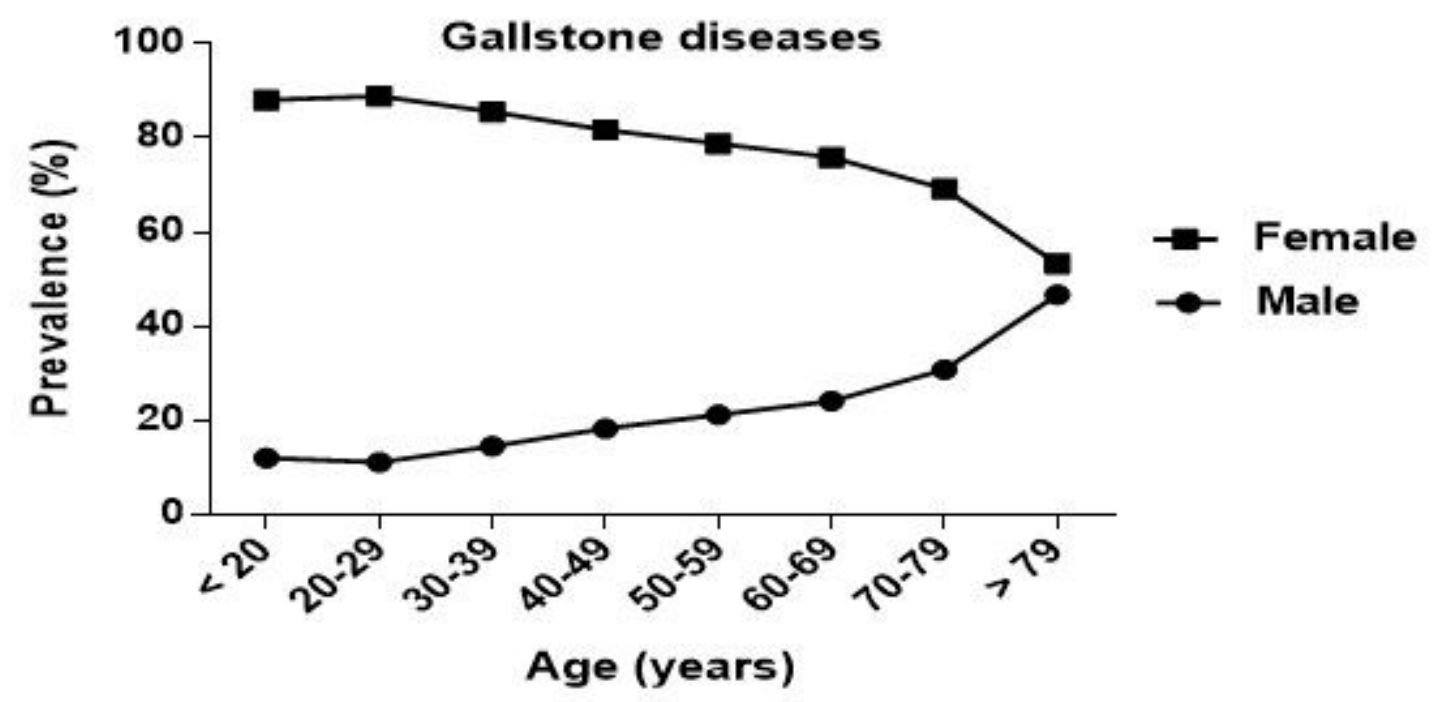

Figure 7

Percentage of patients with cholelithiasis as a function of gender and age among 4044 cases at SPHMC, September 2005 to September 2018. 


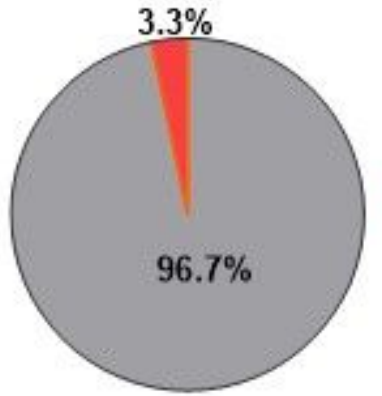

A

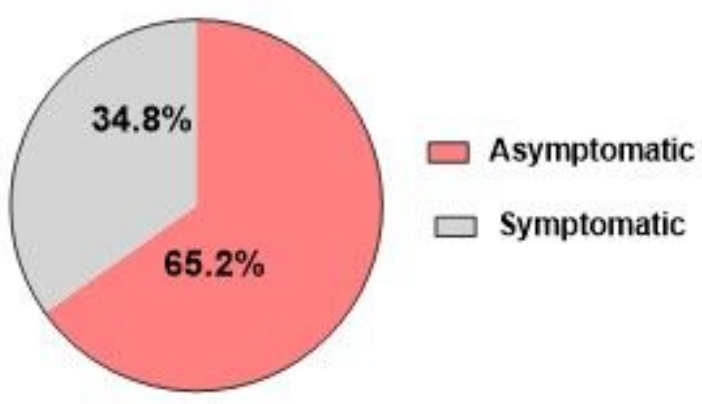

B

Figure 8

Anatomical locations of gallstones (A), and its clinical manifestations (B) among 3287 patients at SPHMC, September 2005 to 2018. [Abbreviation: $C B D=$ Common bile duct] 